\title{
STRATEGI PENGEMBANGAN USAHA PENGOLAHAN KOPI ARABIKA (STUDI KASUS PT GOLDEN MALABAR)
}

\author{
DEVELOPMENT STRATEGIES OF ARABICA COFFEE PROCESSING BUSINESS \\ (A CASE STUDY OF PT GOLDEN MALABAR)
}

\author{
Yuni Dwi Kartika*), Amzul Rifin ${ }^{* *)}$, dan Imam Teguh Saptono***) \\ *) Kementerian Perindustrian Republik Indonesia \\ J1. Jend. Gatot Subroto Kav. 52-53, Jakarta Selatan 12950 \\ ${ }^{* *}$ Departemen Agribisnis, Fakultas Ekonomi dan Manajemen, Institut Pertanian Bogor \\ Jl. Kamper, Wing 4 Level 5, Kampus IPB Darmaga, Bogor 16680 \\ ${ }^{* * * *}$ Sekolah Bisnis, Institut Pertanian Bogor \\ Jl. Raya Pajajaran, Bogor 16151
}

\begin{abstract}
In accommodating coffee seed production, coffee cherry as the main ingredient was collected from personal farms. Nonetheless, as the company's external condition grows, this strategy is no longer appropriate to keep PT Golden Malabar Indonesia growing and developing in current condition in which the consumption rate of coffee has increased and lifestyle has shifted. The main purpose of this research was to formulate strategy development of Arabica coffee processing business. The analysis tools utilized to examine the company's internal and external conditions included the matrices of Internal Factor Evaluation (IFE), External Factor Evaluation (EFE), and Internal-External (IE). The analysis tool used to determine the appropriate strategy for the company was Quantitative Strategic Planning Matrix (QSPM). The total score of IFE matrix of PT Golden Malabar Indonesia was 3.0507 indicating its strong internal position. The total score of EFE matrix of PT Golden Malabar Indonesia was 2.0160 indicating the lack of response to the opportunities and threats outside the company. The position of IE matrix of PT Golden Malabar Indonesia is in region IV in which the company is growing and developing its Arabica coffee processing industry and it is significantly appropriate to conduct integrating strategy. The first priority strategy is in accordance with QSPM analysis i.e. PT Golden Malabar Indonesia is encouraged to perform backward integration by building connection with coffee cherry distribution partners/agents.
\end{abstract}

Keywords: IFE, EFE, QSPM, coffee, Golden Malabar Indonesia

\begin{abstract}
Abstrak: Dalam memenuhi produksi biji kopi, ceri kopi sebagai bahan bakunya diperoleh dari kebun sendiri. Namun seiring berkembangnya kondisi eksternal perusahaan, strategi tersebut sudah tidak tepat untuk membuat PT Golden Malabar Indonesia tumbuh dan berkembang di kondisi saat ini yang meningkatnya konsumsi kopi serta pergeseran gaya hidup. Tujuan utama dari penelitian ini adalah merumuskan strategi pengembangan usaha dari pengolahan kopi arabika. Alat analisis yang digunakan untuk menganalisis kondisi internal dan eksternal perusahaan adalah Matriks Evaluasi Faktor Internal (IFE), Matriks Evaluasi Faktor Eksternal (EFE), dan Matriks Internal-Eksterbal (IE). Alat analisis yang digunakan untuk menentukan strategi yang tepat untuk perusahaan adalah Quantitative Strategic Planning Matrix (QSPM). Total skor matriks IFE PT Golden Malabar Indonesia adalah 3,0507 yang mengindikasikan posisi internal perusahaan yang kuat. Total skor matriks EFE PT Golden Malabar Indonesia adalah 2,0160 hal ini menunjukan bahwa perusahaan belum cukup merespon peluang dan ancaman yang ada di luar perusahaan. Posisi matriks IE PT Golden Malabar Indonesia ada di wilayah IV,dimana perusahaan sedang tumbuh dan berkembang di industri pengolahan kopi arabika, sangat tepat untuk melakukan strategi integrasi. Strategi prioritas pertama sesuai dengan anlisa QSPM, PT Golden Malabar Indonesia sebaiknya melakukan integrasi ke belakang dengan membangun jaringan dengan mitra/agen pemasok ceri kopi.
\end{abstract}

Kata kunci: IFE, EFE, QSPM, kopi, Golden Malabar Indonesia

\footnotetext{
${ }^{1}$ Alamat Korespondensi:

Email: yunidka@gmail.com
} 


\section{PENDAHULUAN}

Kopi merupakan salah satu komoditas perkebunan unggulan Indonesia yang memiliki peranan penting khususnya sebagai sumber devisa, penyedia lapangan kerja, dan sebagai sumber pendapatan bagi petani ataupun pelaku ekonomi lainnya.Pada tahun 2014 Indonesia menjadi produsen kopi keempat terbesar setelah Brazil, Vietnam dan Kolombia. Selain sebagai produsen, padatahun 2015, Indonesia menempati urutan eksportir terbesar ke-5 dalam hal jumlah ekspor produk kopi dengan kode Harmonized System (HS) 0901 setelah Brazil, Vietnam, Kolombia dan Jerman (ITC, 2016).

Industri pengolahan kopi pada umumnya menggunakan bahan baku biji kopi arabika dan robusta dengan komposisi perbandingan tertentu. Teknologi pengolahan kopi pertama kali ditemukan di wilayah timur laut Ethiopia (Talbot, 2002) dan pembudidayaan pertama kali di wilayah selatan Arabia sementara pertama kali menjadi minuman pada pertengahan abad ke 15 di Yaman (Sualeh dan Mekonnen, 2013). Jawa Barat merupakan salah satu provinsi di Indonesia yang memiliki potensi perkebunan dengan kesuburan lahan yang baik serta limpahan potensi sumberdaya alam lainnya. Salah satu perusahaan yang bergerak di bidang perkebunan dan pengolahan kopi arabika yang berlokasi di Kabupaten Bandung, Jawa Barat adalah PT Golden Malabar Indonesia. PT Golden Malabar Indonesia secara resmi berdiri pada tahun 2010 dengan luas lahan sekitar 370 Ha dengan produktivitas biji kopi (green bean) sekitar 60 ton per tahun. Green bean adalah buah dari tanaman kopi yang sudah diproses menjadi biji, juga dikenal dengan sebutan biji kopi mentah.

Strategi yang diterapkan saat ini di PT Golden Malabar Indonesia adalah memasok kopi green bean yang merupakan bahan baku produk roasted bean (kopi sangrai) dan ground (kopi bubuk), dari lahan kebun sendiri. Berbeda dengan PT Sinar Mayang Lestari yang menggunakan strategi pasokan bahan baku sebanyak $20 \%$ dari lahan kebun sendiri dan $80 \%$ dari mitra/agen (Aknesia, 2015). Seiring berkembangnya kondisi eksternal perusahaan, strategi tersebut sudah tidak tepat untuk membuat PT Golden Malabar Indonesia tumbuh dan berkembang di kondisi saat ini yang meningkatnya konsumsi kopi serta pergeseran gaya hidup. Seperti penelitian yang dilakukan oleh Pujiyanto (2007) bahwa keberlanjutan suplai kopi ke pasar sangat ditentukan oleh keberlanjutan produksi di lapangan. Keunggulan kompetitif yang berkelanjutan bisa diterapkan dengan memanfaatkan sumberdaya yang dimiliki (Sandberg dan Abrahamssom, 2011). Perusahaan harus melakukan dan mengembangkan budaya berinovasi untuk memiliki keunggulan bersaing yang berkelanjutan (Hana, 2013).

Penelitian ini terfokus hanya pada strategi pengembangan bisnis ekspor kopi arabika. Lokasi riset di lakukan hanya pada PT Golden Malabar Indonesia yang berlokasi di Kecamatan Pangalengan, Kabupaten Bandung, Jawa Barat.

\section{METODE}

Penelitian dilakukan di PT Golden Malabar Indonesia yang berada di Desa Pasir Mulya Kecamatan Pangalengan Kabupaten Bandung, Jawa Barat Indonesia, dan dilakukan selama 3 bulan, yaitu mulai dari bulan Februari 2016 - April 2016.

Data yang dikumpulkan dalam penelitian ini terdiri dari data primer dan data sekunder. Data Primer, yaitu pengumpulan data yang dilakukan melalui observasi dan wawancara langsung dengan pihak perusahaan dan pihak-pihak yang terlibat dalam strategi pengembangan kopi arabika dengan menggunakan instrumen kuesioner. Data Sekunder diperoleh dari studi pustaka (library research), studi dokumentasi, dan mempelajari data-data yang berasal dari Dinas Perkebunan Provinsi Jawa Barat, Dinas Perindustrian dan Perdagangan, BPS, ICO serta International Trade Centre.

Alat analisis yang digunakan untuk menganalisis kondisi internal dan eksternal perusahaan adalah (a) Matriks Evaluasi Faktor Internal (IFE), (b) Matriks Evaluasi Faktor Eksternal (EFE) dan (c) Matriks Internal-Eksterbal (IE). Sedangkan alat analisis yang digunakan untuk menentukan strategi yang tepat untuk perusahaan adalah Quantitative Strategic Planning Matrix (QSPM).

\section{HASIL}

\section{Analisis Faktor Internal (Analisis VRIO)}

Value, rarity, imitability, dan organization (VRIO) framework disusun dengan sejumlah pertanyaan 
mengenai aktivitas bisnis perusahaan, yaitu mengenai values (nilai), rarity (kelangkaan), imitability (kemungkinan peniruan) dan organisasi. Semua jawaban akan menentukan apakah sebuah sumber daya atau kapabilitas yang dimiliki oleh perusahaan merupakan kekuatan atau kelemahan (Barney, 1991).

\section{Kekuatan (Strength)}

Indikasi Geografis Kekhasan cita rasa dari kopi yang dihasilkan tertuang dalam paten indikasi geografis. Kopi Java Preanger yang menjadi trademark disetiap label produk PT Golden Malabar Indonesia adalah salah satu kekuatan yang dapat dimanfaat meraih pasar pecinta kopi spesial baik di dalam maupun luar negeri.

\section{Produk yang berkualitas}

PT Golden Malabar Indonesia telah menerapkan proses produksi yang baik untuk menjaga kualitas produk yang dihasilkan. Tahun 2014 PT Golden Malabar Indonesia memperoleh Sertifikasi Kompetensi Oleh Badan Nasional Sertifikasi Profesi (BNSP) sebagai Pengolah Kopi (The Beaner Kopi Luwak) Certification Of Luwak Coffee Processing. Selain itu, produk kopi arabika pengolahan biasa PT Golden Malabar Indonesia terpilih sebagai juara dalam kontes kopi spesialti yang diselenggarakan oleh Specialty Coffee Association of Indonesia (SCAI).

\section{Proses inovasi produksi}

Proses produksi yang umumnya dilakukan oleh perusahaan pengolahan kopi arabika adalah proses natural dan semi wash. Menurut Wahyuni et al. (2013) cara pengolahan biji kopi arabika yang menghasilkan mutu kualitas cita rasa yang unik terbaik adalah dengan pengolahan semi wash. Disamping itu, PT Golden Malabar Indonesia membuat produk bernilai tinggi dengan menlakukan proses pengolahan kopi luwak.

\section{Lokasi pabrik yang menguntungkan}

Letak lokasi memiliki kekuatan untuk membuat strategi bisnis sebuah perusahaan. Letak lokasi pabrik dan pengolahan PT Golden Malabar Indonesia di daerah Kabupaten Bandung. Kabupaten Bandung merupakan Kabupaten di daerah Jawa Barat yang memiliki akses transportasinya mudah untuk mendistribusikan produknya, baik di pasar domestik maupun luar negeri.

\section{Kelemahan (Weakness)}

1. Kapasitas perusahaan untuk meningkatkan ekuitas/ modal

PT Golden Malabar Indonesia memiliki aset lahan yang masih dapat digunakan untuk meningkatkan kapasitas produksi kopi. Perusahaan memiliki rencana untuk membuka lahan baru dikarenakan permintaan yang terus bertambah yang tidak diikuti secara bersamaan oleh kenaikan kapasitas produksi, namun perusahaan belum memiliki modal cukup untuk alokasi pembukaan lahan.

\section{Sistem kontrol dan evaluasi}

PT Golden Malabar Indonesia saat ini belum memiliki rancangan strategi tertulis dalam proses pelaksanaan usahanya. Sistem administrasi berupa laporan atau pencatatan yang dimiliki belum tersusun dengan rapi. Namun, sistem kontrol dan evaluasi hanya terbatas diterapkan pada sektor perkebunan, pabrik dan pengolahan dan belum diterapkan pada seluruh komponen yang ada di perusahaan.

\section{Proses rencana strategik}

Perencanaan strategi merupakan faktor internal yang penting untuk dipertimbangkan dalam perencanaan dan pengambilan keputusan. Informasi mengenai target dan tujuan PT Golden Malabar Indonesia yang ingin dicapai belum tersusun secara administratif sehingga informasi belum tersebar sempurna kepada seluruh pegawai.

\section{Kemampuan manajerial}

PT Golden Malabar telah memiliki susunan organisasi serta rancangan proses pelaksanaan usaha. Sistem manajerial yang saat ini ada, masih perlu diperbaharui terkait dengan penyebaran informasi mengenai target dan tujuan perusahaan yang masih bersifat sentralisasi sehingga belum tersebar merata kepada seluruh pegawai. Menurut Negwo et al. (2014) petani kopi harus didorong untuk memperluas informasi untuk memacu produksi kopi, sehingga dapat meningkatkan produksi dan keuntungan.

\section{Analisis Faktor Eksternal (Analisis PESTLE)}

Analisis PEST adalah analisis mengenai kondisi politik, ekonomi, sosial dan teknologi yang dapat memengaruhi 
aktivitas dan kinerja perusahaan. Sedangkan model PESTLE memasukkan aspek lingkungan dan hukum sebagai faktor eksternnal yang kemungkinan akan berdampak pada perusahaan (Rothaermel ,2012).

Hasil analisis PESTLE menunjukkan bahwa peluang (opportunities) yang dimiliki oleh PT Golden Malabar Indonesia, yaitu (1) pasar luar negeri yang terbuka, dimana banyak permintaan dari negara-negara berkembang (2) adanya layanan Pos Ekspor yang dikeluarkan oleh PT Pos Indoneisa dalam melakukan pengiriman barang ke luar negeri dan (3) pergeseran gaya hidup golongan masyarakat dunia dalam mengonsumsi kopi arabika/kopi spesialti. Sedangkan ancaman (threats) yang dihadapi PT Golden Malabar Indonesia saat ini antara lain (1) penguasaan teknologi dan informasi pengolahan kopi yang masih terbatas, (2) infrastruktur pendukung aktivitas, khususnya akses jalan dan (3) persaingan dengan negara penghasil kopi arabika lainnya.

\section{Peluang (Opportunity)}

1. Pasar luar negeri yang terbuka, dimana banyak permintaan dari negara-negara berkembang

Menurut Kustiarti (2007), masih terdapat peluangpeluang untuk pengembangan perkopian Indonesia di masa yang akan datang. Pertama, permintaan produkproduk kopi dan olahannya masih sangat tinggi, terutama di pasar domestik dengan penduduk yang melebihi 200 juta jiwa merupakan pasar potensial. Kedua, peluang ekspor terbuka terutama bagi negaranegara pengimpor wilayah nontradisional seperti Asia Timur, Asia Selatan, Timur Tengah, dan Eropa Timur. Ketiga, kelimpahan sumber daya alam dan letak geografis di wilayah tropis merupakan potensi besar bagi pengembangan agribisnis kopi.

2. Pergeseran gaya hidup golongan masyarakat dunia dalam mengonsumsi kopi arabika/kopi spesialti

Salah satu faktor lain yang memengaruhi pertumbuhan konsumsi kopi adalah adanya pergeseran gaya hidup golongan masyarakat dunia dalam mengonsumsi kopi arabika/kopi spesialti dari budaya peminum kopi menjadi penikmat kopi. Dahulu orang menikmati secangkir kopi di rumah atau warung kopi. Saat ini kopi bisa dinikmati di kafe dan restoran berkelas dengan segmen yang semakin luas, baik dari sisi gender maupun rentang usia. Hal tersebut mendorong konsumsi kopi dalam negeri naik 6 persen sampai 8 persen per tahun.

3. Adanya layanan Pos Ekspor yang dikeluarkan oleh PT Pos Indoneisa dalam melakukan pengiriman barang ke luar negeri

Saluran distribusi merupakan saluran yang digunakan oleh produsen untuk menyalurkan barang tersebut dari produsen sampai ke konsumen atau pemakai industri. PT Golden Malabar Indonesia merespon layanan Pos Ekspor dengan baik karena dapat mengirimkan barangnya ke luar negeri dengan biaya lebih murah dan mudah dibandingkan dengan saluran distribusi lainnya yang ada pada saat ini.

\section{Ancaman (Threats)}

1. Penguasaan teknologi dan informasi pengolahan kopi yang masih terbatas

Teknologi sangat membantu para pengusaha dalam mempercepat proses produksi. Secara nasional, kendala komoditas kopi di Indonesia adalah produktivitas dan kualitas yang masih rendah (Ibrahim dan Zailani, 2010). Teknologi yang digunakan oleh PT Golden Malabar Indonesia saat ini hampir sama dengan yang digunakan oleh perusahaan lain. Dalam proses pengolahan perusahaan menggunakan metode proses luwak dan biasa. Metode proses luwak, yaitu proses pengolahan kopi yang melibatkan hewan liar sejenis musang (luwak). Proses pengolahan kopi biasa terdiri dari proses natural, honey dan semi wash. Proses pengolahan kopi tersebut memerlukan lahan yang luas untuk proses pengeringan serta sinar matahari yang cukup karena masih memanfaatkan sinar matahari secara langsung. Adanya perubahan cuaca akibat pemanasan global akan berdampak pada prose pengolahan.

2. Infrastruktur pendukung aktivitas, khususnya akses jalan

Keunggulan dari kopi arabika adalah cita rasanya yang kuat. Namun, hanya dapat tumbuh di daerah dengan ketinggian diatas $1000 \mathrm{mdpl}$ yaitu daerah pegunungan. Lokasi perkebunan PT Golden Malabar Indonesia yang berada di pegunungan malabar memiliki akses jalan yang agak jauh dari lokasi pabrik sehingga menjadi kendala saat mengantarkan hasil panen ke lokasi pabrik terkait dengan biaya transportasi yang dikeluarkan. 
3. Persaingan dengan negara penghasil kopi

ICO sebagai organiasi kopi dunia setiap tahun mencatat produksi kopi dunia. Saat ini terdapat empat jenis kopi yang aktif diperdagangkan, yakni arabika, robusta, liberika dan excelsa. Sekitar 99\% diantaranya didominasi kopi arabika dan robusta, sisanya liberika dan excelsa. Kedua jenis yang disebutkan terakhir volumenyasangatsedikit sehingga cenderungdiabaikan. Negara penghasil kopi dunia terbesar adalah Brazil, kemudian Vietnam, Kolombia dan Indonesia. Hingga saat ini pangsa pasar ekspor Brazil mencapai 30\% dari total peradagangan kopi global, jauh meninggalkan negara lain. Brazil juga sekaligus menjadi produsen arabika terbesar dunia mengingat sekitar $80 \%$ produksi kopi Brazil merupakan kopi arabika.

\section{Identifikasi Faktor Strategi Eksternal dan Internal}

\section{Matriks Evaluasi Faktor Eksternal}

Hasil dari matriks Evaluasi Faktor Eksternal (EFE) terdapat pada Tabel 2 skor matriks EFE adalah 2.0160. Hal ini menunjukan bahwa PT Golden Malabar Indonesia belum cukup merespon peluang dan ancaman yang ada di luar perusahaan.

\section{Matriks Evaluasi Faktor Internal}

Hasil dari matriks Evaluasi Faktor Eksternal (EFE) terdapat pada Tabel 3 total skor matriks IFE PT Golden Malabar Indonesia adalah 3.0507. Hal ini mengindikasikan posisi internal yang kuat PT Golden Malabar Indonesia.

Tabel 2. Matriks evaluasi faktor eksternal PT Golden Malabar Indonesia

\begin{tabular}{|c|c|c|c|}
\hline Peluang & Bobot & Rating & Skor \\
\hline $\begin{array}{l}\text { Pergeseran gaya hidup golongan masyarakat dunia dalam mengonsumsi kopi arabika / } \\
\text { kopi spesialti }\end{array}$ & 0,1440 & 3 & 0,4320 \\
\hline $\begin{array}{l}\text { Pasar luar negeri yang terbuka, dimana banyak permintaan dari negara-negara } \\
\text { berkembang }\end{array}$ & 0,1839 & 3 & 0,5518 \\
\hline $\begin{array}{l}\text { Adanya layanan POS EKSPOR yang dikeluarkan oleh PT Pos Indoneisa dalam } \\
\text { melakukan pengiriman barang ke luar negeri }\end{array}$ & 0,1920 & 2 & 0,3840 \\
\hline Subtotal & & & 1,3679 \\
\hline Ancaman & Bobot & Rating & Skor \\
\hline Penguasaan teknologi dan informasi pengolahan kopi yang masih terbatas & 0,1600 & 1 & 0,1600 \\
\hline Infrastruktur pendukung aktivitas, khususnya akses jalan & 0,1519 & 1 & 0,1519 \\
\hline Persaingan dengan negara penghasil kopi & 0,1681 & 2 & 0,3361 \\
\hline Subtotal & & & 0,6481 \\
\hline Total & 1,0000 & & 2,0160 \\
\hline
\end{tabular}

Tabel 3. Matriks evaluasi faktor internal PT Golden Malabar Indonesia

\begin{tabular}{lccc}
\hline Kekuatan & Bobot & Rating & Skor \\
\hline Lokasi pabrik yang menguntungkan & 0,1734 & 3 & 0,5201 \\
Proses inovasi produksi & 0,1734 & 4 & 0,6935 \\
Produk berkualitas & 0,1835 & 4 & 0,7339 \\
Indikasi Geografis & 0,1635 & 4 & 0,6540 \\
\hline Subtotal & & & 2,6016 \\
\hline Kelemahan & Bobot & Rating & Skor \\
\hline Kapasitas perusahaan untuk meningkatkan ekuitas/modal & 0,0920 & 1 & 0,0920 \\
Kemampuan manajerial & 0,0714 & 2 & 0,1429 \\
Sistem kontrol dan evaluasi yang baik & 0,0714 & 1 & 0,0714 \\
Proses rencana strategik yang efektif & 0,0714 & 2 & 0,1429 \\
\hline Subtotal & & & 0,4491 \\
\hline Total & 1,0000 & & 3,0507 \\
\hline
\end{tabular}




\section{Matriks Internal Eksternal (IE)}

Matriks IE (Internal-External) memposisikan berbagai divisi suatu organisasi dalam tampilan sembilan sel. Matriks IE didasarkan pada dua dimensi kunci: skor bobot IFE total pada sumbu $\mathrm{x}$ dan skor bobot EFE total pada sumbu $\mathrm{y}$.

Berdasarkan Gambar 1, diketahui bahwa PT Golden Malabar Indonesia berada di kuadran empat, yaitu dengan strategi intensif dan integritas (Sel IV). strategi intensif dan integritas merupakan strategi pertumbuhan dan pembangunan dimana perusahaan memperluas daerah pemasaran dan meningkatkan kemampuannya baik di hulu dengan meningkatkan pasokan bahan baku maupun di hilir yaitu jaringan distribusi.

\section{Prioritas Strategi Bisnis PT Golden Malabar Indonesia (QSPM)}

Hasil identifikasi faktor internal dan eksternal, lalu diolah dengan matrik Internal dan Eksternal, tahap terakhir adalah tahap memilih strategi yang utama yang diperoleh melalui analisis QSPM. Hasil QSPM PT Golden Malabar Indonesia selengkapnya pada Tabel 3.
1. Melakukan integrasike belakang dengan membangun jaringan dengan mitra/agen pemasok ceri kopi

Integrasi belakang adalah upaya kepemilikian usaha yang dapat membantu pasokan untuk usaha perusahaan. PT Golden Malabar Indonesia saat ini memenuhi kebutuhan produksi dari kebun sendiri dan menjual langsung kepada konsumen langsung sehingga rantai pemasarannya pendek. Semakin pendek rantai tataniaga menyebabkan adanya kemampuan untuk menentukan harga (Drajat dan Herman, 2009).

2.Melakukanintegrasikedepandenganmengembangkan usaha produk kopi roasting, ground (bubuk) dan siap minum serta membangun café.

Mendapatkan kepemilikan atau meningkatkan kontrol atas penjalur atau penjual eceran. Strategi integrasi ke depan adalah strategi yang dijalankan dengan meraih kendali atas jalur distribusi, mulai dari distributor hingga retailer. Analisis harga pada produk olahan biji kopi arabika menunjukkan bahwa produk lanjutan dari green bean memiliki nilai tambah lebih tinggi. Peningkatan konsumsi kopi arabika diiringi dengan pertumbuhan coffee shop di Indonesia menjadi peluang PT Golden Malabar Indonesia untuk melakukan strategi integrasi ke depan.

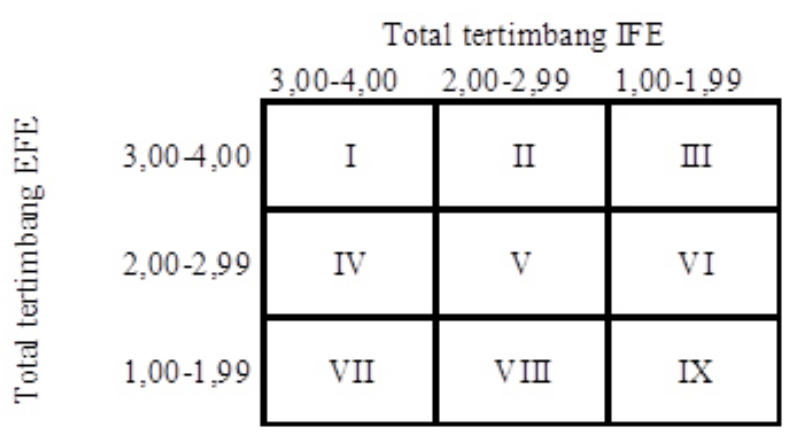

Gambar 1. Matriks IE PT Golden Malabar Indonesia

Tabel 3. Hasil QSPM PT Golden Malabar Indonesia

\begin{tabular}{|c|c|c|c|}
\hline & Strategi Alternatif (SA) & TAS & Peringkat \\
\hline $\begin{array}{l}\text { Backward Integration } \\
\text { Strategy }\end{array}$ & $\begin{array}{l}\text { Melakukan integrasi ke belakang dengan membangun jaringan } \\
\text { dengan mitra/agen pemasok ceri kopi }\end{array}$ & 7,0628 & 1 \\
\hline $\begin{array}{l}\text { Forward Integration } \\
\text { Strategy }\end{array}$ & $\begin{array}{l}\text { Melakukan integrasi ke depan dengan mengembangkan usaha } \\
\text { produk kopi roasting, ground (bubuk) dan siap minum serta } \\
\text { membangun café }\end{array}$ & 6,7996 & 3 \\
\hline Market Penetration Strategy & $\begin{array}{l}\text { Meningkatkan pangsa pasar yang ada dalam rangka penetrasi } \\
\text { pasar kopi arabika }\end{array}$ & 6,6034 & 4 \\
\hline $\begin{array}{l}\text { Market Development } \\
\text { Strategy }\end{array}$ & $\begin{array}{l}\text { Memperkenalkan produk kopi arabika di daerah pemasaran baru } \\
\text { sebagai strategi pengembangan pasar }\end{array}$ & 6,4343 & 5 \\
\hline $\begin{array}{l}\text { Product Development } \\
\text { Strategy }\end{array}$ & $\begin{array}{l}\text { Pengembangan produk pengolahan kopi arabika melalui riset } \\
\text { dan pengembangan }\end{array}$ & 6,9073 & 2 \\
\hline
\end{tabular}


3. Meningkatkan pangsa pasar yang ada dalam rangka penetrasi pasar kopi arabika

Strategi penetrasi pasar dijalankan untuk meningkatkan pangsa pasar yang ada untuk produk tertentu melalui usaha pemasaran secara besar-besaran. kegiatan yang dapat dilakukan PT Golden Malabar Indonesia adalah melakukan promosi dan edukasi mengenai kopi arabika luwak dan kopi arabika biasa yang menjadi unggulannya. Dalam era globalisasi, pemasaran konvensional sangat tidak efisien dan efektif untuk digunakan karena memiliki banyak kekurangan, seperti biaya promosi yang mahal atau kendala ruang dan waktu dalam proses pemasaran (Salehi et al. 2012)

Memperkenalkan produk kopi arabika di daerah pemasaran baru sebagai strategi pengembangan pasar Memperkenalkan produk-produk yang sudah ada kedaerah pemasaran yang baru (pangsa pasar bertambah). Strategi Pengembangan pasar ke new market ini dijalankan dengan memperluas area geografi baru, menambah segmen baru, mengubah dari bukan pemakai menjadi pemakai, menarik pelanggannya pesaing. Menurut Hakim (2003) beberapa hal yang perlu diperhatikan dalam strategi pemasaran kopi menghadapi isu global adalah strategi internal (ke dalam negeri) berupa konversi tanaman pengembangan kopi arabika, dan peningkatan konsumsi domestik; serta strategi eksternal (ke luar negeri) dengan menjaga pangsa pasar, terobosan pasar baru, dan pengembangan kerjasama bilateral dan multilateral.

\section{Pengembangan produk pengolahan kopi arabika melalui riset dan pengembangan}

Meningkatkan penjualan dengan cara memperbaiki atau mengembangkan produk-produk yang sudah ada. Strategi yang dijalankan untuk menaikkan penjualan dengan memperbaiki atau memodifikasi produk yang ada saat ini. Menjalankan strategi ini berarti melibatkan pengeluaran biaya penelitian dan pengembangan yang besar. Misalnya dengan pengembangan kemasan produk yang digunakan untuk pasar ekspor yang lebih menarik ataupun pengembangan cita rasa kopi sesuai dengan permintaan konsumen seperti spesifikasi produk kopi yang diminati di Australia adalah produk kopi hasil fermentasi 24 jam.

\section{KESIMPULAN DAN SARAN}

\section{Kesimpulan}

PT Golden Malabar Indonesia memiliki total skor matriks IFE adalah 3,0507 yangmengindikasikan posisi internal perusahaan yang kuat. Total skor matriks EFE PT Golden Malabar Indonesia adalah 2,0160. Hal ini menunjukan bahwa perusahaan belum cukup merespon peluang dan ancaman yang ada di luar perusahaan.

Posisi matriks IE PT Golden Malabar Indonesia ada di wilayah IV, dimana perusahaan sedang tumbuh dan berkembang di industri pengolahan kopi arabika, sangat tepat untuk melakukan strategi integrasi. Strategi prioritas pertama sesuai dengan anlisa QSPM, PT Golden Malabar Indonesia sebaiknya melakukan integrasi ke belakang dengan membangun jaringan dengan mitra/agen pemasok ceri kopi.

\section{Saran}

Saran yang dapat diberikan untuk perusahaan yaitu untuk lebih jeli dalam melihat perubahan yang terjadi dalam lingkungan bisnis PT Golden Malabar Indonesia. Perusahaan dapat melakukan integrasi ke belakang dengan membangun jaringan dengan mitra/agen pemasok ceri kopi. Perusahaan dapat memulai untuk melihat potensi agen/petani pasokan ceri yang dapat dijadikan mitra untuk menjaga ketersediaan bahan baku. Di samping itu, perlu juga untuk memperbaiki sistem organisasi dalam perusahaan.

\section{DAFTAR PUSTAKA}

Aknesia V, Daryanto A, Kirbrandoko. 2015. Business development strategy for specialty coffee. Indonesian Journal of Business and Entrepreneurship 1(1): 12-22. https://doi. org/10.17358/IJBE.1.1.12.

Barney JB. 1991. Firm resources and sustained competitive advantage. Journal of Management 7: 99-120. https://doi. org/10.1177/014920639101700108.

Drajat B, Herman. 2009. Keragaan dan usulan alternatif strategi pengembangan bisnis ekspor kakao Indonesia. Pelita Perkebunan 23: 139-159.

Hakim N. 2003. Strategi pemasaran kopi dalam menghadapi over supply, isu ecolabelling dan isu ochratoxin. Warta Penelitian Kopi dan Kakao 9 
(1): 22-38.

Hana U. 2013. Competitive advantage achievement through innovation and knowledge. Journal of Competitiveness 5(1): 82-96. https://doi. org/10.7441/joc.2013.01.06.

Ibrahim H, Zailani S. 2010. A Review on the competitiveness of global supply chain in a coffee industry in Indonesia. International Business Management Medwell Journals 4(3): 105-115.

Negwo JC, Anakalo AS, Evans B, Nemwel NA. 2014. Effect of farm succession on coffee production in Kisii County Kenya. International Journal of Agricultural Extension 2(3): 183-191.
Pujiyanto. 2007. Arah menuju produksi kopi berkelanjutan. Warta Pusat Penelitian Kopi dan Kakao Indonesia 23(1): 1-10.

Sualeh A., Mekonnen N. 2013. Evaluation of coffee quality of Tigray Regional State, Ethiopia (case study Raya Azebo District). Prudence Journal of Agricultural Research 1(2): 3-6.

Talbot J.M. 2002. Coffee crisis: the case for a regulated market. Georgetown Journal of International Affairs 3(1): 45-52.

Wahyuni E, Abubakar K, Ashabul A. 2013. Analisis citarasa kopi arabika organik pada beberapa tempat dan cara pengolahannya di Dataran Tinggi Gayo. Jurnal Manajemen Sumberdaya Lahan 2(3): 261-269. 